\title{
No tan polarizados. Los gobiernos de Evo Morales y los medios de comunicación en Bolivia*
}

Not so polarized. The Evo Morales' Governements

and the Media in Bolivia

\section{IVÁN SCHULIAQUER**}

Universidad Nacional de San Martín, Argentina.

Consejo Nacional de Investigaciones Científicas y Técnicas, Argentina.

ischuliaquer@unsam.edu.ar

https://doi.org/10.46468/rsaap.14.2.A5

Los vínculos entre los gobiernos de Evo Morales y los medios en Bolivia, pasaron de una confrontación pública (2006-2009) a una negociación amable (2009-2016). Este artículo historiza esa relación a través de los sistemas mediáticos nacionales, la comunicación política y las politicas de comunicación.

Bolivia se distingue de otros casos del "giro a la izquierda" sudamericano porque los medios no fueron protagonistas de la polarización política, sino uno de sus escenarios. Para eso jugaron tres cuestiones. Una, el peso relativo fuerte del Estado y la centralidad del gobierno. Dos, la estrategia de los empresarios mediáticos que, ante un gobierno de signo político contrario al de su línea editorial, aceptaron reglas de juego que les resultaban convenientes. Tres, la autorregulación del trabajo periodístico que limita la intervención sobre los contenidos de otros actores. El artículo cierra con una coda dedicada a lo que sucedió cuando Evo Morales fue derrocado.

\section{Introducción}

La relación entre los gobiernos de izquierda y los grandes grupos mediáticos nacionales a principios del siglo XXI en Sudamérica se caracterizó por un enfrentamiento público donde se disputaban la representación de la realidad y de la ciudadanía. En ese contexto de polarización política, los gobiernos tensionaron las reglas de juego de los vínculos con los medios de comunicación y los señalaron como parte central de su oposición. Más

* Artículo recibido el 13 de junio de 2020 y aceptado para su publicación el 28 de octubre de 2020.

** El autor agradece el aporte de dos evaluaciones anónimas a una versión previa de este artículo. 
allá de esa continuidad, las relaciones entre esos actores fueron diferentes según el país.

Este artículo indaga en el vínculo que establecieron los gobiernos de Evo Morales con los medios de comunicación en Bolivia. Nos detenemos en la primera década de gobierno: desde el arribo a la presidencia hasta su primera derrota electoral a nivel nacional. Distinguimos dos períodos: el primero (2006-2009) se caracterizó por la confrontación, en tanto el segundo (2009-2016) estuvo marcado por una negociación amable.

Aunque distintos autores caracterizaron al caso boliviano como uno de los más radicales dentro del "giro a la izquierda" sudamericano (Levitsky y Roberts, 2011), los gobiernos del Movimiento al Socialismo (MAS) se distinguen de otros casos considerados también dentro de los más radicales como los del kirchnerismo en Argentina, el correísmo en Ecuador y el chavismo en Venezuela- porque no tuvieron una relación polarizada con los principales grupos mediáticos nacionales.

¿Cómo explicar esta relación no polarizada entre gobierno y principales grupos mediáticos bolivianos? El abordaje teórico-metodológico que proponemos estudia la "negociación de las escenas mediáticas", a la que entendemos como la interacción conflictiva entre distintos actores sociales por disputar y definir las políticas de comunicación y la comunicación política. Allí intervienen y confluyen sus poderes relativos, sus ideologías, sus intereses, sus repertorios de acción — posibles e imaginables-y sus voluntades (Schuliaquer, 2018).

En este artículo proponemos un modelo propio para definir los sistemas mediáticos nacionales que, aplicado al caso boliviano, resalta particularidades que inciden en la negociación de las escenas mediáticas y permite señalar tres razones principales por las que los medios no fueron protagonistas de la polarización, sino uno de sus escenarios.

Primero, porque el peso relativo de los gobiernos es mucho mayor al de los grandes grupos mediáticos para imponer parte de las condiciones de ese vínculo. En Bolivia esto se dio históricamente así, algo que fue aún más marcado desde 2009 por el fortalecimiento político y económico del Estado y por la centralidad del gobierno en ese proceso.

Segundo, por la manera en que se establecen las mesas de negociación entre medios y política, donde también intervienen los partidos y el periodismo político. En el período estudiado, Bolivia se caracterizó por la centralidad excluyente del presidente en el escenario político, por el peso débil de la oposición político-partidaria, por la centralidad de un periodismo que considera que lo central de su trabajo pasa por obtener los testimonios de los políticos — sobre todo del gobierno- y no de denunciarlos, así como por la manera en que los periodistas como colectivo - a través de 
mecanismos de autorregulación-impiden la intervención directa sobre los contenidos de propietarios y de poderes políticos.

Tercero, por la forma en que los gobiernos, los grupos mediáticos privados y los periodistas políticos percibieron que los afectaría un cambio en las reglas de juego. Todos tuvieron, sobre todo desde 2009, pocos incentivos para romper radicalmente las reglas de vínculos que les resultaron convenientes.

A partir de aquí, el artículo se divide en seis partes. En la primera, presentamos el abordaje teórico-metodológico y una breve revisión bibliográfica. En la segunda, proponemos un modelo para definir al sistema mediático nacional y lo aplicamos a Bolivia. En la tercera nos detenemos en la comunicación política durante los gobiernos del MAS y en la cuarta en las políticas de comunicación. En la quinta parte se presenta, como conclusión, la forma que tomó la negociación de las escenas mediáticas en Bolivia entre 2006 y 2016. En la sexta, se agrega una coda que indaga en el vínculo entre medios y política hasta noviembre de 2019, cuando Evo Morales fue derrocado.

\section{Abordaje teórico-metodológico}

Entre 1999 y 2007, distintos países de la región giraron a la izquierda: Venezuela, Brasil, Argentina, Uruguay, Bolivia y Ecuador ${ }^{1}$. Se trató de gobiernos que aparecieron tras experiencias neoliberales, expandieron políticas desarrollistas, redistributivas y de bienestar social (Levitsky y Roberts, 2011) y confluyeron en una ola de reincorporación de los sectores populares y su participación política (Rossi, 2017).

Como señala críticamente Kitzberger (2012), la relación entre medios y política en algunos países fue leída en ciertos casos bajo el señalamiento del componente "populista" de esos gobiernos, antes que estudiada en profundidad a través de la configuración que tomó ese vínculo. Aquí indagamos en la ideología de esos gobiernos, pero también en su poder relativo y las oportunidades políticas y restricciones con las que contaron en la interacción con otros actores, ya que eso influyó sobre sus estrategias en cuestiones de medios y política (Kitzberger, 2012; Vommaro y Schuliaquer, 2014).

Nos referimos a los gobiernos de Hugo Chávez en Venezuela (1999-2013), de Lula da Silva y Dilma Rousseff en Brasil (2003-2016), de Néstor Kirchner y Cristina Fernández en Argentina (2003-2015), de Tabaré Vázquez y José Mujica en Uruguay (2005-2020), de Evo Morales en Bolivia (2006-2019) y de Rafael Correa en Ecuador (2007-2017). Como dice Bobbio (1996), la diferencia entre izquierda y derecha se basa en la postura ante la desigualdad: mientras para la izquierda es un problema a corregir, para la derecha es una consecuencia de la libertad. 
Aunque el crecimiento sostenido de los flujos comunicacionales internacionales es notable, gran parte de los problemas de medios y política se siguen organizando a escala nacional (Waisbord, 2013). Si bien en la actualidad la masificación de medios digitales y redes sociales permitieron formas de comunicación menos mediadas de las que se valen la mayoría de los referentes políticos, ese no era el escenario en Bolivia para 2005 cuando Evo Morales ganó las elecciones. Es más, hasta 2016 no tuvo cuenta personal en las redes sociales. ${ }^{2}$

El arribo de fuerzas de izquierda a los gobiernos en la región se dio tras una época caracterizada por la consagración de la televisión como un espacio central de la política (Vommaro, 2008). Sin embargo, las teorías que habían señalado que esa forma de la política había llegado para quedarse como lógica dominante (Sartori, 1998) tenían serias dificultades para explicar la tensión entre los gobiernos de izquierda y los grandes grupos mediáticos. Por un lado, porque esos gobiernos señalaron a esos grupos como su principal oposición política ${ }^{3}$ y, no obstante, ganaron al menos tres elecciones presidenciales consecutivas. Por otro lado porque, antes de la masificación de las redes sociales, esos gobiernos modificaron la forma de participar en las escenas mediáticas: cuestionaron el rol central del estudio de televisión y, en línea con las movilizaciones sociales previas a su arribo a la presidencia, buscaron mostrarse en copresencia de la ciudadanía movilizada (Schuliaquer, 2014).

El gobierno de izquierda de Bolivia se caracterizó por una hibridación entre el marco heredado y un proyecto estatista y redistributivo (Levitsky y Roberts, 2011), que tuvo un componente refundacional (Sader, 2009) que incluyó, en su problematización pública, una asimilación de la élite política previa con la élite mediática. A pesar de ello, luego de tres años de confrontación entre gobierno y empresas de medios, en los siete años siguientes el gobierno se sintió bien tratado por la mayoría de los medios privados.

Este trabajo retoma dos de las perspectivas más desarrolladas para estudiar las cuestiones de medios tradicionales y política en la región desde inicios del siglo XXI. En la primera de ellas, autores identificados con el estudio de la comunicación política analizaron la relación entre Estado, gobiernos y empresas mediáticas. Algunos lo hicieron a través de casos nacionales (Exeni, 2010; Molina, 2015; Porto, 2012; Vommaro, 2008), otros a partir de trabajos comparativos (Fox y Waisbord, 2002; Guerrero, 2014;

El presidente creó su cuenta de Twitter en abril de 2016 y la de Facebook en enero de 2018.

3 Eso no los privó de combinar ese señalamiento con estrategias pragmáticas de acomodación para influir sobre cómo serían tratados en esos grandes medios (Porto, 2012; Goldstein, 2014; Schuliaquer, 2018). 
Kitzberger, 2012). La segunda perspectiva analizó específicamente las políticas de comunicación. En algunos casos a través de la economía política, que observó la estructura de propiedad (Becerra y Mastrini, 2006), y en otros casos a partir de la regulación legal (Segura y Waisbord, 2016).

El abordaje teórico-metodológico que proponemos estudia la "negociación de las escenas mediáticas" (Schuliaquer, 2018). Para caracterizarla proponemos indagar en tres dimensiones.

La primera son los sistemas mediáticos nacionales: el terreno histórico, cultural y material de la negociación. En este caso, caracterizamos la configuración del campo político boliviano - a partir del peso relativo del Estado sobre los medios y de la centralidad de la mediación partidaria- y la de su campo mediático - a través de la estructura de propiedad de las empresas comunicacionales, de sus líneas editoriales, así como del tipo de periodismo político que prima.

La segunda y la tercera dimensión se detienen en la negociación de las escenas mediáticas mismas. Los actores de mayor peso en esa negociación en Sudamérica son los gobiernos y los grandes grupos mediáticos nacionales. Estudiar las políticas de comunicación y la comunicación política al mismo tiempo es central, tanto porque las políticas de reforma e intervención mediática de los gobiernos no pueden entenderse separadas de sus formas de aparición mediática, como porque las escenas de los medios privados no están completamente separadas de sus intereses como actores políticos-comerciales.

Aunque ambas dimensiones se solapan e interactúan entre sí, es necesario separarlas analíticamente. Entonces, la segunda dimensión es la comunicación política, que se explora a través de las estrategias de aparición mediática de los gobiernos y de las maneras en las que son representados en las escenas de los medios privados. Y la tercera dimensión es la vinculada a las políticas de comunicación, a través de las cuales se analizan las estrategias políticas y comerciales de los grandes grupos mediáticos nacionales y las políticas de regulación, reforma e intervención mediática de los gobiernos.

Para historizar el vínculo entre medios y política en Bolivia entre 2006 y 2016, este artículo se nutre de entrevistas semiestructuradas y en profundidad con actores clave, así como de un seguimiento de producciones mediáticas y de discursos gubernamentales. Esto fue complementado tanto con una exploración de los cambios regulatorios y la intervención de los gobiernos del MAS en el sistema mediático, como con un relevamiento de las vías privilegiadas por el gobierno para sus apariciones mediáticas.

El trabajo de campo contó con una estancia en septiembre y octubre de 2015 en la ciudad de La Paz. Se hicieron veintidós entrevistas on the record con actores clave: políticos, funcionarios, periodistas, directores de medios, 
académicos. En ese momento se realizaron observaciones de campo —visitas al parlamento, participación en actos políticos, visitas a redacciones y canales de televisión $n^{4}$. La mayoría de las entrevistas fueron realizadas cara a cara, lo cual fue complementado en 2015 con entrevistas vía Skype con personas que vivían en Santa Cruz de la Sierra o que estaban de viaje cuando el autor estuvo en La Paz.

En el próximo apartado presentamos nuestro modelo para definir los sistemas mediáticos nacionales y lo aplicamos a Bolivia.

\section{El sistema mediático nacional boliviano}

El sistema mediático nacional es una unidad de análisis que identifica relaciones críticas entre medios y política ancladas en torno al Estado (Waisbord, 2013). Para estudiarlos de manera comparada, el trabajo de Hallin y Mancini (2004) es una referencia ineludible. Sin embargo, ese estudio se detiene en Europa occidental, Estados Unidos y Canadá y no se aplica directamente a otras regiones (Hallin y Mancini, 2012). Pese a eso, Hallin y Papathanasopoulos (2002) sugieren que América Latina tiene un modelo cercano al de países europeos del Mediterráneo, llamado "pluralista polarizado", que combina una prensa de baja circulación, un claro paralelismo político —o equivalencia ideológica— entre medios y organizaciones políticas, una débil profesionalización periodística y un Estado que interviene fuertemente. Más cerca en el tiempo, otros autores han caracterizado a los sistemas mediáticos de la región como "liberales capturados" (Guerrero, 2014), en tanto combinan normativas liberales y modelos privado-comerciales, pero en la práctica funcionan de otra forma: la regulación mediática y el rol del periodismo como contralor suelen quedar subsumidos a los intereses de gobiernos y empresarios mediáticos. Sin negar que esa combinación se encuentra presente en la región, las diferencias entre los países latinoamericanos muchas veces son marcadas y significativas (Schuliaquer, 2018). Por lo tanto, si se acerca el foco, es difícil pensar que un solo modelo pueda definir todos los sistemas latinoamericanos. Por eso, proponemos un modelo que da lugar a las características distintivas de cada caso. Siguiendo a Della Porta (2008), nuestra propuesta comparativa está más orientada a los casos que a las variables, en ser exhaustivos antes que abarcadores. También porque los vínculos entre gobiernos y medios se encuentran histórica y territorialmente situados y los sistemas no están definidos de una vez y para siempre. Si bien ellos inciden sobre la negociación de las escenas, esa negoFueron fundamentales las redes de contactos que me facilitaron el historiador Pablo
Stefanoni y el diputado del MAS Manuel Canelas. 


\section{Iván Schuliaquer}

ciación afecta y reconfigura, a su vez, a los sistemas. Aunque en este artículo solo nos detenemos en el caso boliviano, entendemos que el modelo de análisis que proponemos es aplicable a otros países y a otras épocas históricas. Como se observa en la Tabla 1, el modelo se concentra en la configuración del campo político y del campo mediático.

\section{TABLA 1}

Sistemas mediáticos nacionales

\begin{tabular}{|c|c|c|}
\hline Estructuración & Dimensión & Subdimensión \\
\hline \multirow[t]{5}{*}{ Campo político } & \multirow{2}{*}{$\begin{array}{l}\text { Peso relativo del } \\
\text { Estado sobre el } \\
\text { campo mediático }\end{array}$} & $\begin{array}{l}\text { Rol histórico del Estado en la } \\
\text { configuración del mercado mediático }\end{array}$ \\
\hline & & Propiedad mediática y peso económico \\
\hline & \multirow{3}{*}{$\begin{array}{l}\text { Centralidad de la } \\
\text { mediación } \\
\text { partidaria }\end{array}$} & Centralidad histórica de los partidos \\
\hline & & $\begin{array}{l}\text { Crisis de representatividad del sistema } \\
\text { partidario }\end{array}$ \\
\hline & & Estructuración del partido de gobierno \\
\hline \multirow[t]{5}{*}{ Campo mediático } & \multirow{2}{*}{$\begin{array}{l}\text { Estructuración de } \\
\text { las empresas } \\
\text { mediáticas }\end{array}$} & $\begin{array}{l}\text { Configuración del gran grupo mediático } \\
\text { nacional }\end{array}$ \\
\hline & & $\begin{array}{l}\text { Estabilidad de la propiedad y de la línea } \\
\text { editorial }\end{array}$ \\
\hline & \multirow[t]{3}{*}{$\begin{array}{l}\text { Configuración del } \\
\text { periodismo político }\end{array}$} & $\begin{array}{l}\text { Tipo de periodismo que prima (noticias } \\
\text { más jerarquizadas y vías de adquirir } \\
\text { notoriedad, relación entre políticos y } \\
\text { periodistas) }\end{array}$ \\
\hline & & ¿Presencia de vedettes periodísticas? \\
\hline & & $\begin{array}{l}\text { Tipo de profesionalización (división } \\
\text { entre opinión e información y entre el } \\
\text { área comercial y la periodística) }\end{array}$ \\
\hline
\end{tabular}

Fuente: elaboración propia.

A partir de aquí, analizamos la configuración del sistema mediático boliviano para cuando el MAS llegó al gobierno en 2006. 


\section{III.1. La estructuración del campo político}

\section{A. El peso relativo del Estado sobre el campo mediático}

La historia de las políticas de comunicación en América Latina muestra que los grandes grupos mediáticos privados tuvieron un rol clave en ellas y fueron sus principales beneficiarios (Waisbord, 2013). Los Estados tuvieron un rol constitutivo en los sistemas mediáticos mediante la entrega de licencias y recursos a aliados (Hallin y Papathanassopoulos, 2002). Más allá de esa continuidad, su peso relativo varía en cada país, algo que incide sobre los recursos con los que cuentan los gobiernos para negociar. Para definir ese peso relativo indagamos en dos subdimensiones. La primera historiza el rol del Estado sobre la configuración del sistema mediático. La segunda caracteriza la propiedad y el peso económico del Estado en el campo mediático a partir de tres indicadores. El primero refiere a la propiedad estatal en las industrias infocomunicacionales. El segundo indicador es la inversión del Estado en relación al PBI, una manera de observar su peso sobre la economía nacional. El tercer indicador refiere a la importancia de la pauta publicitaria estatal sobre el total del mercado, en países con débil o inexistente regulación de la publicidad oficial, y una tradición de definición discrecional de parte de los gobiernos.

En Bolivia, durante las experiencias neoliberales, que empezaron en 1985 y se profundizaron una década después, se debilitó el peso del Estado sobre la organización de la vida social. Para ello había sido clave la capitalización de distintas empresas. Entre ellas, tanto la de la Empresa Nacional de Telecomunicaciones (Entel), como la privatización de distintos medios en manos estatales (Mastrini y Becerra, 2006). Aunque históricamente Bolivia fue el país más pobre de Sudamérica, el Estado era, a escala relativa, un actor más central para la economía que en otros países sudamericanos. Esto aumentaría durante los gobiernos del MAS.

Entre los recursos a distribuir, el Estado jugaba un rol central como anunciante, jerarquizado también por el débil peso económico del mercado publicitario boliviano (Molina, 2015). La ausencia de datos sistematizados no quita su importancia para los distintos medios: como se desprende de distintas entrevistas con investigadores, editores y periodistas, no contar con ellos ponía en riesgo su supervivencia, ya que representaba al menos el $50 \%$ de sus ingresos. 
B. La centralidad de la mediación partidaria

Cuanto menor sea la centralidad de la mediación partidaria, mayor será el de otras instancias de articulación de lo político (Laclau, 2008), y viceversa. En ese marco, puede crecer el peso de los líderes políticos y el de los medios tradicionales.

La pérdida de centralidad de los partidos políticos como espacio de constitución de las identidades sociales se da a escala global (Rosanvallon, 2015), pero no es igual en todos los países. Para determinar la centralidad de la mediación partidaria, utilizamos tres subdimensiones. La primera se detiene en la centralidad histórica de los partidos y su perdurabilidad. La segunda se pregunta por la crisis de representatividad del sistema partidario para cuando arribaron los gobiernos de izquierda. La tercera caracteriza la estructuración del partido gobernante para conocer el vínculo que los gobiernos establecen con la fuerza política propia.

La emergencia del liderazgo de Evo Morales, de origen en el sindicalismo campesino, se dio en el marco de la crisis de la "democracia pactada". Se llamó así a los diferentes acuerdos entre élites políticas y partidarias, que habían sido previamente opositoras y que gobernaron con acuerdos parlamentarios desde 1985 hasta 2003. Es decir, desde la salida de la dictadura hasta el fin del consenso neoliberal en Bolivia. Fue un período de una estabilidad inédita para el país (Stefanoni y Do Alto, 2006), aunque el sistema de partidos no había funcionado como uno de representación de la sociedad civil (Zegada, 2006). De hecho, las mayorías indígenas habían sido débilmente representadas.

Para el quiebre de esa representatividad, habían sido clave diferentes movimientos que ocuparon el lugar central que había tenido la Central Obrera Boliviana en décadas previas (Stefanoni, 2005). Para entonces, se había expandido en la sociedad un discurso sobre "la descolonización del Estado, la autorrepresentación indígena-popular y la nacionalización de los recursos naturales" (Stefanoni y Do Alto, 2006:25). Movimientos sociales organizados para incluir a pobres y subrepresentados armaron un partido para acceder a la esfera estatal con menos mediaciones (Anria, 2018).

Esta fase de movilización tuvo dos hitos fundamentales que marcaron "el comienzo del cambio en la correlación de fuerzas ideológicas y sociales" (Svampa et al, 2010:11). En 2000, la "guerra del agua", cuando distintos sectores protestaron contra el aumento exponencial de las tarifas de agua en Cochabamba, controlada por la trasnacional Bechtel, expulsada tras estos hechos. La organización se dio en torno a una nueva agregación de demandas sociales y nuevas conformaciones políticas y sociales en las que el movimiento cocalero, comandado por Evo Morales, jugó un rol central (Stefanoni y Do Alto, 2006). 
En 2003, la "guerra del gas" implicó otro ciclo de movilizaciones en el marco de la crisis social y económica, en oposición a la decisión de exportar gas por puertos chilenos ${ }^{5}$. El presidente Gonzalo Sánchez de Lozada renunció a su cargo y dejó el país. De allí surgió la llamada "agenda de octubre", que tenía en su centro la recuperación de los recursos naturales para el Estado y el llamado a una asamblea constituyente que proponía incorporar a los excluidos desde la fundación de Bolivia en 1825 (Stefanoni y Do Alto, 2006). El por entonces vicepresidente Carlos Mesa, periodista televisivo y ex accionista del canal PAT, continuaría el gobierno hasta 2005, cuando renunció y lo reemplazó Eduardo Rodríguez Veltzé, hasta entonces presidente de la Corte Suprema.

En ese contexto de crisis institucional, Evo Morales fue elegido presidente con $53.7 \%$ de los votos en primera vuelta. Superar el $50 \%$ de los votos, algo inédito desde el regreso de la democracia, le permitió contar con mayoría parlamentaria propia. Por primera vez, un indígena - que representaban $62 \%$ de la población según el censo 2001— presidiría Bolivia. Su vicepresidente era el intelectual Álvaro García Linera, proveniente de una familia de clase media mestiza.

La crisis del orden previo se canalizó a partir de nuevos actores, en un marco de polarización creciente, con un discurso antisistema y contrario a los partidos tradicionales (Zegada y Komadina, 2014). La llegada de Morales al gobierno implicó un recambio radical de élites dirigentes: el capital político provenía de la experiencia social en organizaciones campesinas, obreras e indígenas, no de la "meritocracia profesional" previa (Zegada y Komadina, 2014:63). Es decir, más allá de la centralidad creciente de los principales líderes, las raíces del partido en los movimientos sociales jugaron un rol central a través de mecanismos de "abajo hacia arriba" (Anria, 2018).

\section{III.2. La estructuración del campo mediático}

\section{Empresas de medios y estabilidad}

En América Latina priman los medios privado-comerciales (Exeni, 2005). Esto se profundizó con la aplicación de políticas neoliberales (Fox y Waisbord, 2002), en una región con altos niveles de concentración de la propiedad (Mastrini y Becerra, 2006) y donde la consolidación de la democracia no fue acompañada de una democratización de los medios (Fox y Waisbord, 2002).

Para indagar en el poder relativo de los grandes grupos mediáticos nacionales, nos detenemos en dos subdimensiones. La primera se pregunta

$5 \quad$ Chile le quitó a Bolivia su salida al mar en la guerra del Pacífico (1879-1883). 
quiénes son los actores privados de mayor escala y de qué forma están constituidos. La segunda profundiza en dos cuestiones. Por una parte, en la estabilidad histórica de la propiedad mediática: cuanto menor sea, mayor posibilidad habrá de que el recambio aparezca como parte de los repertorios de acción. Por otra parte, en la estabilidad de la línea editorial en el tratamiento de las distintas fuerzas políticas (Albuquerque, 2013).

Para el inicio del período estudiado, Bolivia contaba con el nivel más bajo de facturación en las industrias informativas y con la mayor diversidad en cantidad de propietarios de Sudamérica (Mastrini y Becerra, 2006). Son excepcionales los casos en los que una misma empresa es líder en distintas esferas mediáticas y se destacan los medios regionales, a tono con la separación histórica del país entre Santa Cruz, como su centro económico, y La Paz, como su centro político. Los propietarios de medios en Bolivia suelen ser las familias más acaudaladas del país, de vínculos cercanos con las fuerzas políticas tradicionales (Villanueva, 2008). En ese marco, sus actividades más rentables no son las mediáticas. Algunos de ellos son propietarios de bancos, administradoras de fondos de pensión, aerolíneas, empresas de minería, grandes extensiones de tierra, y muchos fueron funcionarios durante la "democracia pactada" (Lupien, 2013).

Para el inicio del período (2006), los cuatro canales más vistos eran Unitel, Red Uno y PAT — todos de Santa Cruz- y ATB — de La Paz-; los diarios más vendidos eran El Deber de Santa Cruz, La Razón de La Paz, Los Tiempos de Cochabamba y La Prensa de La Paz (Becerra y Mastrini, 2009).

Cuando Evo Morales llegó al gobierno existían dos grupos mediáticos salientes. Uno era de la familia Garafulic y contaba con el Canal ATB y los diarios La Razón y Extra de La Paz, además de otros medios gráficos en Cochabamba y Santa Cruz (Ramos Andrade, 2011). A partir de 2000, el grupo español Prisa sería socio de ese conglomerado. Para entonces también, para contrapesar el peso de los Garafulic (Giavedoni, 2010), nació el Grupo Líder, con una agenda menos dependiente del poder político (Archondo, 2003). Los Rivero y los Canelas, con base en El Deber de Santa Cruz y Los Tiempos de Cochabamba, reunían nueve diarios, $40 \%$ de los títulos del país (Ramos Andrade, 2011). Por lo tanto, en Bolivia no encontramos grandes grupos mediáticos nacionales comparables en su concentración a los que sí existen en otros países como Argentina y Brasil.

El acceso a los medios en Bolivia por parte de las audiencias estaba entre los más bajos de Sudamérica (Becerra y Mastrini, 2009), lo que se complementaba con la fuerte presencia y tradición de radios comunitarias y locales. Un caso paradigmático era la red Erbol, con 70 emisoras y una de las más escuchadas del país. 


\section{El periodismo político en Bolivia}

Como señala Lemieux (2010), el periodismo no es una profesión liberal en el sentido clásico: comparte características del trabajo en serie con elementos del trabajo artesanal.

Para analizar el periodismo político, proponemos tres subdimensiones. La primera se enfoca en el tipo de periodismo que prima y explora, por un lado, cuáles son las noticias más jerarquizadas por los medios y, por otro, si la relación que se establece entre políticos y periodistas es más de cooperación o de competencia. La segunda subdimensión examina si las vedettes periodísticas ocupan un lugar jerarquizado en los medios. Estos periodistas se caracterizan por mostrarse como los representantes de la ciudadanía ante "los políticos" (Vommaro, 2008) y por movilizar, al mismo tiempo, discursos informativos y de opinión. La tercera subdimensión se detiene sobre la autonomía del periodismo a partir de dos cuestiones. La primera refiere a la distinción entre los discursos de opinión y los de información; la segunda a la separación entre el área empresarial y el área informativa.

Cuando el MAS llegó al gobierno, el componente principal del periodismo boliviano era el de reportería: las noticias más jerarquizadas solían ser las declaraciones de las figuras políticas. No obstante, para 2005, con la crisis, los actores de la política institucional perdieron legitimidad. En ese marco, el crecimiento de la popularidad de Evo Morales a nivel nacional fue inescindible de su participación mediática, donde aparecía como una voz jerarquizada de los sectores movilizados. Para ello colaboró el "periodismo de declaración”, caracterizado por la cooperación entre políticos y periodistas y el beneficio mutuo. Los políticos porque sus declaraciones definen parte importante de los contenidos de sus apariciones mediáticas. Los periodistas porque al obtener esas declaraciones se distinguen del resto de sus colegas.

Históricamente, el periodismo de investigación tuvo una débil presencia en Bolivia (Molina, 2015), aunque sí jugaba un rol central la consideración de que los periodistas debían ser contralores de los políticos (entrevistas con Raúl Peñaranda, periodista y analista, director de Página Siete 20102013; Claudia Benavente, directora de La Razón desde 20106).

A la vez, en Bolivia existe una separación marcada en las prácticas entre el trabajo informativo y el de opinión. Para la mayoría de los periodistas, su

Para evitar repeticiones, solo se presentará el cargo de entrevistados/as cuando se los referencie por primera vez. Si las entrevistas no indican fecha y lugar es porque fueron hechas entre septiembre y octubre de 2015 en La Paz. Cuando no sea el caso, se lo indicará. También, a los fines expositivos, omitiremos decir "entrevista propia" aunque siempre que refiramos a "entrevista" hablaremos de aquellas que hizo el autor de este artículo. 
tarea es reportear. Sin embargo, esa distinción entre opinión e información no se sostiene para las vedettes periodísticas que, ante la crisis de la representación política institucional, disputaron parte de la representación legítima de la ciudadanía. Un ejemplo paradigmático es Carlos Mesa, que pasó de presentador televisivo a presidente. ${ }^{7}$

A tono con otras ramas laborales en Bolivia, los periodistas están organizados como colectivo y uno de sus objetivos es resguardar sus condiciones profesionales (entrevistas con José Luis Exeni, académico; Marcelo Tedesqui, editor de $E l$ Deber $)^{8}$. En algunos casos, cuando hubo acuerdos entre sectores políticos y grupos mediáticos para una cobertura beneficiosa, los periodistas se movilizaron y reclamaron que se respete su labor ${ }^{9}$. Así reivindicaron la autorregulación de su trabajo, algo que fue acompañado de tribunales de ética y honor propios (Exeni, 2010).

Ante la crisis, los distintos medios habían dado más espacio a diferentes analistas: figuras intelectuales, periodísticas y políticas que eran colocadas como intérpretes privilegiadas de la época. Frente a planteles periodísticos que se autorregulaban, las vedettes y los analistas eran los principales vehículos de los propietarios para intervenir sobre sus medios.

\section{III.3. El sistema mediático}

Para cuando Evo Morales llegó al gobierno, el sistema mediático boliviano se caracterizaba por un fuerte peso relativo del Estado sobre la esfera mediática y la debilidad de la centralidad partidaria, contrapesada por la importancia de otras instancias de mediación, varias veces corporativas, como los sindicatos. Esto se complementaba con medios regionalizados en un mercado fragmentado, sin grupos líderes coincidentes en distintas áreas mediáticas. Por último, a tono con la falta de consenso de la época, confluían un periodismo de reportería — que jerarquizaba la declaración de los políticos- y la presencia de vedettes periodísticas que disputaban la representatividad de la ciudadanía.

7 En una conversación off the record con otra vedette, le pregunté si pensaba candidatearse a presidente, pese a que nunca había sido parte de un partido político. Su respuesta fue que no lo haría porque, aunque podía ganar las elecciones, no lo dejarían gobernar.

$8 \quad$ Están asociados en dos organizaciones principales: la Asociación de Periodistas de La Paz, donde participan los periodistas de mayor renombre, y la Federación de Trabajadores de la Prensa, de lógica más sindical. También existe la Asociación Nacional de la Prensa, integrada por directores y propietarios.

9 Archondo (2003) cuenta cómo los periodistas de La Razón, durante el gobierno democrático del ex dictador Hugo Banzer (1997-2001), le dijeron al propietario (Garafulic) que o les daba mayor libertad para reportear sobre el gobierno o renunciaban todos. 


\section{La comunicación política de los gobiernos del MAS (2006-2016)}

Los vínculos entre los gobiernos de Evo Morales y los medios pasaron de una confrontación pública (2006-2009) a una negociación amable (20092016). Para explorar la comunicación política nos detenemos en dos cuestiones: las estrategias de aparición mediática del gobierno y las escenas de los grandes grupos mediáticos privados sobre política nacional.

Antes de llegar a la presidencia, Evo Morales se preocupó por su vínculo con los medios. Como líder sindical, cultivó relaciones de cercanía con algunos cronistas - antes que con jefes periodísticos y propietarios- por los que se sentía bien tratado. Consideraba que ellos lograban negociar con líneas editoriales ideológicamente contrarias a los movimientos sociales a los que representaba, al tiempo que aprovechaba la importancia que para la escala baja de la profesión tenían las declaraciones de las figuras políticas para ganar notoriedad.

Sin embargo, cuando llegó al gobierno propuso un traslado de las escenas de los medios a las calles y los actos de gobierno, en línea con el período de movilización que comenzó en 2000. Como la figura excluyente de la política boliviana, se hizo seguir ${ }^{10}$ y se mostró en copresencia de la ciudadanía. Parte de su agenda incluía visitar cada día una localidad diferente del país: el presidente visibilizaba lugares que habían quedado fuera de los medios.

Morales daba conferencias de prensa y discursos públicos constantemente. Era parte de los cambios simbólicos buscados, una forma de confrontar los cuestionamientos a su capacidad, y la de los indígenas, de expresarse públicamente:

Yo dije: "tienen que aceptarlo al Evo como es, así hablando, no hay que domesticarlo. Tiene que ser así”. El primer año Evo ha dado más de mil declaraciones de prensa. En la mañana tres, en la tarde otras tres (entrevista con Walter Chávez, asesor de comunicación de Morales hasta 2015).

Junto con ello, el gobierno problematizó el rol político de los medios, a los que señaló como sus principales opositores ${ }^{11}$. Para eso contaba con la narrativa histórica de los movimientos sociales: emparentar los intereses de las empresas mediáticas con los del statu quo anterior no fue disruptivo ni novedoso. La cobertura de las elecciones de 2005 colaboró con la narrativa gubernamental. El reporteo fue balanceado, pero en la opinión y análisis, los medios comerciales prefirieron claramente a sus contrincantes (Onadem, 2009).

10 Una de los ejemplos más claros fue el 1 de mayo de 2006 cuando anunció, desde un pozo petrolífero, la nacionalización de los hidrocarburos.

11 En su discurso de asunción los acusó de haber tratado a los indígenas como salvajes, y tiempo después aseguró: "El enemigo número uno de Evo son la mayoría de los medios" (Rocha, 2014:105). 
Desde el inicio, Morales distinguió a los periodistas de los medios en que trabajaban y los consideró partidarios suyos. Algo que los mismos periodistas no siempre compartieron y ante lo que el presidente manifestó públicamente su decepción (entrevistas con Fernando Molina, periodista e investigador de medios y política; Boris Miranda, periodista de La Prensa y de Página Siete, noviembre de 2015).

En la primera etapa (2006-2009), el gobierno consideró que no podía negociar sus apariciones mediáticas de forma aceptable. El panorama político boliviano estaba caracterizado por el "empate catastrófico" (García Linera, 2010) entre el nuevo bloque de poder y las élites tradicionales de los departamentos orientales - Santa Cruz, Tarija, Pando y Beni-, que enfrentaron al gobierno con contenidos sectoriales y racistas (Svampa et al, 2010). Esto incluyó, en sus casos más extremos, el asesinato de indígenas en Pando. Durante ese período, por ejemplo, el presidente no podía visitar esos departamentos (entrevista con Walter Chávez; Sivak, 2014).

En esa etapa los diarios más vendidos se opusieron editorialmente a las propuestas del gobierno (Onadem, 2009) y los medios cruceños de mayor audiencia apoyaron la agenda autonómica de la élite regional, de la cual muchos de los propietarios eran parte.

Sin embargo, las normas periodísticas y la poca presencia del periodismo de denuncia limitaron la incidencia de esos propietarios. Por lo tanto, ese enfoque antigubernamental no apareció desde los contenidos informativos que producían los periodistas rasos, sino desde el framing de los titulares, de los temas a los que dedicarían (o no) espacio, así como desde los discursos de los analistas.

Los canales PAT y Red Uno señalaron que el dilema era entre autonomistas demócratas y masistas, y Unitel fue poco plural (Peñaranda, 2009). Esos medios presentaron a los partidarios del gobierno como actores manipulados e irracionales (Lupien, 2013). Los discursos que sostenían al gobierno aparecían desde medios menos masivos, como el estatal Bolivia Televisión o la red de radios Erbol, y señalaban a los que apoyaban las autonomías como "separatistas y oligarcas" (Onadem, 2009: 134). Aunque de manera desbalanceada por su tamaño y alcance, los medios reproducían los clivajes del campo político, no los producían.

El medio más equilibrado había sido el diario El Deber. Pese a su línea editorial conservadora, fue un espacio privilegiado por el masismo, que consideró que podía negociar su participación y llegar a un público no cercano políticamente (entrevistas con Amanda Dávila, ministra de Comunicaciones 2011-2015; Manuel Canelas, diputado del MAS; Pablo Ortiz, periodista de El Deber, noviembre de 2015). A la vez, el presidente y el vicepresidente jerarquizaron su participación en el canal estadounidense CNN en español. 
Era una forma de incidir sobre lo que se decía de Bolivia en el exterior, pero también de participar sobre la agenda nacional: era el canal informativo más visto en un país sin canales de noticias 24 horas y con cadenas regionalizadas.

Entre 2008 y 2009, en un marco de amenazas a la gobernabilidad, tres victorias electorales contundentes del gobierno modificaron el panorama del país ${ }^{12}$. Desde entonces, el gobierno se consideró tratado de manera favorable en la mayoría de los medios. Por entonces, Evo Morales, que en pleno conflicto había dejado de atender a los periodistas de medios bolivianos, volvió a dar entrevistas. Las empresas mediáticas aceptaron ese nuevo orden al que, en muchos casos, se habían confrontado sin éxito. Eso implicó un triunfo del periodismo de declaración que consideraba que la noticia más jerarquizada eran los testimonios de los líderes políticos y, sobre todo, del presidente. Durante esta etapa, incluso los medios antes señalados como opositores eran considerados "una prensa muy respetuosa, con un trabajo muy profesional" (entrevista con Amanda Dávila). Fue un escenario favorable para el gobierno, en tiempos de hegemonía política, con una oposición derrotada y desarticulada.

Pese a ese marco, ante los intentos fallidos del gobierno de quitar subsidios a la gasolina (en 2010) y de construir una ruta que pase por el parque nacional TIPNIS (en 2011), hubo masivas manifestaciones en su contra que lo enfrentaron con algunos sectores de su base social. El presidente dio marcha atrás, prueba también del poder de actores de base del MAS para incidir en el curso del gobierno (Anria, 2018). En ese contexto, hubo una ruptura con algunos medios y periodistas que lo habían apoyado en el período de polarización política (entrevistas con Andrés Gómez, director de Erbol 2003-2015; Raúl Peñaranda; Amalia Pando). Un caso paradigmático fue Erbol, cuya audiencia principal eran sectores de base e indígenas.

Tras el fortalecimiento político del gobierno, las vedettes periodísticas que se le oponían tuvieron dificultades para encontrar espacios en los medios. Por un lado, porque algunas habían quedado deslegitimadas por su rol durante el período de polarización y porque los empresarios redujeron los espacios para figuras con juego de representatividad propio que confrontaran con el gobierno. Como dijimos, la selección de analistas y vedettes es una de las herramientas principales de los propietarios para incidir en la línea editorial. Por otro lado, porque el gobierno denunció públicamente a

12 En agosto de 2008, el gobierno llamó a una revocatoria de mandatos. Evo Morales obtuvo $67.4 \%$ de votos a favor. Luego, en enero de 2009 la nueva Constitución fue refrendada con $61.4 \%$ de los votos. En diciembre de 2009, el gobierno obtuvo su reelección (para 2010-2015) bajo la nueva Constitución con 64.2\% de los votos en primera vuelta. 
algunas vedettes que lo habían apoyado en tiempos de polarización y que ahora se presentaban disputando su representatividad política ${ }^{13}$.

La ruptura con esos actores, no obstante, es la excepción a mesas compartidas entre los distintos sectores desde 2009. No hubo escena mediática dividida en Bolivia entre oficialismo y oposición: los hechos centrales de la política fueron compartidos. Lo que difería era la interpretación.

En ese contexto, la credibilidad siguió siendo un valor a defender en la tarea periodística, así como lo fue brindar una contraparte. En los casos en los que las notas tenían errores, fue habitual que los medios se retractaran. Cuando un actor se consideraba afectado, contaba con la posibilidad de réplica, incorporado como derecho constitucional y de uso habitual desde $2009^{14}$. Había distintos mecanismos de control cruzado y normas profesionales compartidas entre la mayoría de los periodistas, junto con instancias de organización colectiva. La escena mediática era más plural que antes: actores que habían sido históricamente subrepresentados tenían mayor visibilidad. Sobre todo en los medios estatales y de línea editorial cercana al gobierno, pero no solo en ellos.

Para el final del período, el gobierno señalaba que sus principales opositores eran dos radios asociativas de origen católico — Erbol y Fides - ${ }^{15}$ y un diario que no era el más vendido - Página Siete. Es decir, se consideraba bien tratado en la mayoría de los medios. Evo Morales dejó claro su parecer:

Antes sentía que el 80 o $90 \%$ de los medios eran mis opositores. Ahora quedan $10 \%$ o $20 \%$ de opositores. No es que necesite apoyo, sino que digan la verdad. (El Deber, 24 de septiembre de 2013).

\section{Las políticas de comunicación de los gobiernos del MAS (2006-2016)}

Para analizar las políticas de comunicación durante los gobiernos de Evo Morales, nos focalizamos en dos dimensiones. Una, las políticas de regulación, distribución de recursos y reforma mediática del gobierno. Dos, las estrategias políticas y comerciales de los grandes grupos mediáticos bolivianos.

13 Así son los casos de Raúl Peñaranda y de Amalia Pando. Ambos renunciaron a los medios para los que trabajaban. Amalia Pando llevó su programa, Cabildeo, a los medios digitales, un espacio desde el que logró sostener cierta masividad.

14 Era habitual que los entrevistados grabaran los reportajes como forma de tener un documento para eventualmente pedir réplica. Cuando entrevisté a la diputada de Unidad Demócrata Jimena Costa, su jefe de prensa acercó un grabador para registrar la charla. La legisladora le dijo que no se moleste, que era para un trabajo académico.

15 Esto fue coherente con las relaciones tensas que tuvo la Iglesia con el gobierno. 
Cuando Evo Morales comenzó su gobierno en 2006, algunos de los propietarios de los medios más importantes se acercaron para negociar "la paz" a partir de beneficios mutuos: buen tratamiento para el gobierno a cambio de recursos para las empresas (entrevista con Walter Chávez). A contramano de sus antecesores, el gobierno se negó a pactar y, durante toda la década, Morales nunca se reunió con los propietarios de medios (Molina, $2015)^{16}$.

Esto fue acompañado de estrategias de intervención sobre los medios informativos, por arriba y por abajo. Desde arriba, se fortaleció a los medios estatales, con Canal 7, Radio Patria Nueva — conectada con redes localesy la creación del diario Cambio. Todos ellos hablaban desde imaginarios poco presentes en la mayoría de los medios bolivianos, pero con fuerte pregnancia en distintas organizaciones sociales. Eso incluyó, por ejemplo, que mujeres con pollera fueran presentadoras de los programas (entrevista con Gustavo Iván Portocarrero, director de Bolivia TV ${ }^{17}$. Luego del punto de ruptura de 2009, los medios estatales se oficializarían fuertemente: Canal 7 tendría su programación organizada en torno de las actividades del presidente y de otros funcionarios de alto rango. Para la mayoría de los periodistas, el canal funcionó como fuente para seguir al presidente: bastaba con verlo para conocer sus actividades y declaraciones (entrevistas con Marcelo Tedesqui; Juan Carlos Salazar, director de Página Siete 2013-2016). Por abajo, el gobierno impulsó la creación de radios comunitarias, sobre todo en áreas rurales, ligadas a movimientos sociales e indígenas. Esa red contó con 92 emisoras.

En 2008, como había hecho con los hidrocarburos, el gobierno nacionalizó la Empresa Nacional de Telecomunicaciones (Entel), privatizada en 1995. Se trataba de la empresa líder en telefonía móvil, fija y servicios de venta de internet ${ }^{18}$. Desde entonces, creció a ritmo sostenido: para 2015, controlaba $46 \%$ de las telecomunicaciones bolivianas. Con Entel, el Estado pasó de no tener propiedad directa en el mercado comunicacional más rentable, a ser su principal protagonista. A eso sumaba su capacidad regulatoria y el manejo de recursos. Entre ellos, uno especialmente relevante en la cotidianeidad de los medios era la publicidad oficial que, en un marco de crecimiento sostenido del $\mathrm{PBI}^{19}$ y con más empresas estatales, aumentó su peso.

16 Eso cambiaría en febrero de 2016, tras la derrota en el referendo que buscaba modificar la Constitución.

17 Un antecedente fue el canal Radio Televisión Popular (RTP), fundado en 1985. Fue un espacio de expresión mediática de sectores indígenas, pero también de representación política: de ahí nació el partido Conciencia de Patria (Condepa).

18 En 2015, lanzaría el servicio de televisión satelital.

19 El crecimiento del PBI fue de $4.8 \%$ anual en promedio entre 2006 y 2016 . El mejor momento económico de la historia de Bolivia (Molina, 2013). 
Entre 2007 y 2008, la estrategia política de varios de los medios privados más importantes fue apostar a la salida anticipada del gobierno. Luego, pasaron a una fase defensiva de preservación del statu quo, tanto para proteger sus negocios en otras áreas, como para conseguir publicidad oficial.

Los gobiernos del MAS impulsaron nuevas regulaciones mediáticas. La primera apareció en la nueva Constitución, a partir de dos artículos que ponderaban el derecho a la comunicación, modificando el paradigma de la libertad de prensa y comprometiendo al Estado en la creación de medios comunitarios. La normativa tuvo poca oposición pública; fueron otras partes de la Constitución las que ocuparon el centro del debate.

La legislación que sí tuvo más oposición fue la Ley contra el Racismo y toda forma de Discriminación de 2010. Impulsada por organizaciones sociales cercanas al oficialismo, versaba sobre distintos temas y tenía dos artículos que establecían sanciones para los medios que las incumplieran. Un día antes de la votación en la Asamblea, la mayoría de los diarios salió con una misma portada en blanco que decía "No hay democracia sin libertad de expresión". En un contexto en que el consenso antirracista era muy elevado tras los sucesos de 2008-2009, los actores mediáticos quedaron aislados en su reclamo.

Inspirados por las experiencias de otros países de la región — sobre todo Argentina-, sectores de la sociedad civil buscaron proponer una ley marco para los medios. No obstante, no lograron apoyo ni de gremios periodísticos, ni de sectores académicos, ni de organizaciones sociales que sí estaban de acuerdo con una regulación, pero no con una basada en los estándares aceptados internacionalmente. A eso se sumó la decisiva negativa de los líderes del gobierno (entrevistas con José Luis Exeni y Verónica Rocha, académicos): un cambio regulatorio podía traer un alto costo político, en un contexto en que la negociación de las escenas era beneficiosa.

En 2011, el gobierno sí avanzaría con una norma marco: la Ley General de Telecomunicaciones, Tecnologías de Información y Comunicación, que conllevó distintos cambios en el panorama regulatorio. Por un lado, dividió el espectro en tres sectores iguales: privado, estatal y sin fin de lucro. Por otro, puso un plazo temporal a las licencias de radiodifusión. La oposición a la norma vino desde las empresas, sin éxito. Los periodistas no se plegaron y las escenas mediáticas de los medios no fueron controladas por el discurso de los propietarios. Por entonces, la preocupación de los periodistas como colectivo organizado se basaba en resguardar la Ley de Imprenta, "la madre de todas las batallas" (entrevista con Marcelo Tedesqui). Considerada patrimonio del gremio (entrevista con José Luis Exeni), permitía que no hubiera delitos de imprenta y que las cuestiones ligadas a publicaciones fueran resueltas en un tribunal especial y propio. Las repetidas aclaraciones públicas 
de que el gobierno no modificaría la Ley de Imprenta, fueron también una prueba de la distinción que hacían entre ellos y los empresarios. ${ }^{20}$

Para 2009, el Grupo Líder como tal se había desmembrado, el Grupo Garafulic lo había hecho previamente, y el gobierno y los grandes medios privados modificaron su vínculo. En el nuevo marco, los empresarios mediáticos recibían ciertos recursos mientras buscaban resguardar sus posiciones. El buen tratamiento que recibió el gobierno no implicó una oficialización de sus líneas editoriales, sino una baja de la radicalización política contra el gobierno y una primacía del discurso de reportería por sobre el de opinión y el de disputa directa de la representatividad.

Luego del punto de ruptura, hubo cambios en la propiedad de algunos medios, algo coherente con la inestabilidad histórica boliviana. Por ejemplo, el canal ATB y el diario La Razón de La Paz fueron adquiridos por empresarios cuyo desembarco en el país coincidió con sus inversiones en otras áreas más rentables en términos comerciales (Peñaranda, 2014) y confluyó con la estrategia global del Grupo Prisa de desprenderse de parte de sus activos en Sudamérica. Desde entonces, la línea editorial de esos medios pasó a ser más cercana al gobierno, pero sin que ello supusiera modificar las normas profesionales periodísticas ni suspender el pluralismo interno (observación en la redacción de La Razón). Una diferencia marcada con la modificación que la participación gubernamental había generado en otros países.

Por otra parte, en 2010 la familia Garafulic sacó Página Siete, diario que canalizó parte de las voces más críticas y que sería considerado por el gobierno como su principal opositor en esa segunda etapa ${ }^{21}$. Para 2015, era uno de los tres medios que no recibían pauta publicitaria, junto con las radios Erbol y Fides.

Durante la segunda presidencia de Morales, cinco actores fueron los más beneficiados por la pauta oficial. En un país sin mediciones validadas, el gobierno aseguraba que se trataba de los medios de mayor audiencia (entrevista con Amanda Dávila). Por un lado, los ya mencionados ATB y $L a$ Razón. Por el otro, la radio Panamericana, el canal Unitel y el diario El Deber, todos medios de líneas editoriales no oficialistas, pero con los que el gobierno consideró que negociaba las escenas de manera aceptable. Eso era coherente con una concepción del gobierno en distintos terrenos, que parece

20 En 2012, el gobierno impulsó dos normas en favor de los periodistas: el pago de un seguro de vida e invalidez obligatorio y el pago del transporte para quienes trabajaban en horario nocturno (Rocha, 2014).

21 Para 2015, distintos actores, con datos privados, coincidían en que los diarios más leídos eran El Deber y La Razón (entrevistas con Marcelo Tedesqui; Claudia Benavente). Eso era refrendado por su lugar, entre 2013 y 2016, como los sitios web de noticias más visitados (Quiroga, 2017). 
haber sido su estrategia también en el mediático: a los empresarios no se los puede conquistar, pero sí neutralizar (García Linera, 2016).

Como había pasado previamente, también había programas de debate donde participaban distintos sectores políticos. Un ejemplo era "Esta casa no es hotel", de ATB, donde Morales dio varias entrevistas exclusivas. La diferencia con un tiempo anterior no pasaba por la falta de pluralismo, sino porque en esta etapa era administrado desde un sentido común cercano al MAS.

El dominio político del gobierno sería refrendado en octubre de 2014 cuando Morales fue reelegido con $61.3 \%$ de los votos en primera vuelta para el período 2015-2020.

\section{La negociación de las escenas mediáticas en Bolivia (2006-2016)}

Tal como pasó con su hegemonía política, el vínculo del MAS con los medios comenzó a agrietarse en febrero de 2016. A un año de haber asumido un nuevo mandato, el gobierno convocó a un referendo para modificar la Constitución y permitirle a Evo Morales presentarse a una nueva reelección. Por primera vez desde que llegó a la presidencia, el líder del MAS perdió una elección nacional: el "No" venció al "Sî" 51.3\% a 48.7\%.

Por entonces, un tema central de la agenda fue el "Caso Gabriela Zapata”. A veinte días de la elección, la vedette periodística Carlos Valverde denunció, desde su programa en el canal Activa de Santa Cruz, a Evo Morales por tráfico de influencias en favor de una empresa contratista china. La prueba que daba era que la gerenta comercial de la compañía, Gabriela Zapata (hasta entonces desconocida públicamente), había tenido un hijo con Morales. El presidente negó el tráfico de influencias, pero respondió que era cierto lo de su hijo y que, lamentablemente, le habían dicho que se había muerto.

La cuestión ocupó el centro de la agenda mediática. Nuevamente, la disputa en los medios tradicionales estuvo antes en las opiniones y el ángulo de la información que en la información en sí misma. Los diversos medios estuvieron de acuerdo en su relevancia y la jerarquizaron en sus espacios. Pasadas las elecciones de febrero, se supo que ese hijo nunca existió. Fue el propio periodista Valverde quien lo anunció y denunció que Zapata le había mentido al acercarle la información.

Ante una denuncia de una vedette muy crítica del presidente, el gobierno no negó los hechos ni descalificó a su emisor, salió a disputar la versión de los mismos. Tras la desmentida pública, Valverde se retractó. La disputa no era sobre cuáles eran los hechos centrales de la política, sino sobre su interpretación. 
Días después, Evo Morales aseguró que su derrota se explicaba por las redes sociales ${ }^{22}$. Es decir, cuando buscó responsables, no señaló a los medios tradicionales ni a ciertos periodistas que, como él, habían dado por buena la información sobre ese hijo.

La aparición de noticias falsas que perjudican a los gobiernos en el marco de una elección presidencial fue moneda corriente en los años 2010 en Sudamérica. ${ }^{23}$ Lo distintivo del caso boliviano es el acuerdo respecto de los temas centrales de la agenda política y de lo que había que hacer cuando una información se probaba falsa para recomponer la legitimidad y credibilidad.

Para explicar por qué hubo consenso sobre los hechos centrales de la política boliviana hasta 2016 y por qué los medios no fueron protagonistas de la polarización, sino uno de sus escenarios, respondemos tres preguntas que permiten explicar tanto la manera en que la configuración del sistema mediático nacional incidió sobre la comunicación política y las políticas de comunicación, como la dinámica que tomó la interacción entre actores en la negociación de las escenas mediáticas. Uno, ¿̇cuál es el peso relativo de los gobiernos y los grandes grupos mediáticos sobre la definición de la escena mediática? Dos, ¿de qué manera se establecen las mesas de negociación y cómo se dan las articulaciones de grandes grupos mediáticos, gobiernos, periodismo político y fuerzas políticas? Tres, ¿cómo perciben el gobierno y los grandes grupos mediáticos que los afectaría una modificación de las reglas de juego para negociar las escenas?

Primero, en Bolivia el poder relativo del Estado es mayor al de los grupos mediáticos. Eso le dio al gobierno un poder diferencial. Por un lado, porque el Estado es central para la economía, por los recursos que distribuye, por su crecimiento económico durante el período y por su peso sobre las telecomunicaciones con la reestatización de Entel. Por otro lado, porque no hay un gran grupo mediático nacional de peso a escala relativa comparable a los de otros países de la región — como Argentina o Brasil- Ni en su peso sobre los medios informativos ni en su tamaño de mercado.

Segundo, en Bolivia prima un periodismo político de reportería, que no se caracteriza por la denuncia y jerarquiza las declaraciones de los políticos

AGETIC (2017) señala que entre 2012 y 2016 se duplicó el acceso hogareño a internet, aunque solo llegaba a $23 \%$, pese a que el acceso a través de celulares permitía la participación del $67 \%$ de la población. No obstante, la televisión seguía siendo el principal medio de información política: llegaba al 95\% de los hogares y era considerado el más confiable por la mayoría de los bolivianos.

23 Por ejemplo, en Brasil, la revista Veja publicó dos días antes de las elecciones que Dilma Rousseff conocía toda la operación de corrupción Lava Jato, algo que luego se probó falso. En Argentina, el programa Periodismo Para Todos de Canal 13, del Grupo Clarín, acusó al por entonces jefe de gabinete y candidato a gobernador de la Provincia de Buenos Aires de haber cometido un triple crimen ligado al narcotráfico, algo que también se probó falso. 
más salientes como parte central de su trabajo. Como colectivo, los periodistas ponen límites a la intervención de los propietarios o el gobierno sobre el contenido informativo. Eso estuvo en tensión en tiempos de polarización —2007-2009—, pero, luego, el periodismo de reportería permitió que el gobierno diera su versión bajo normas caracterizadas por la búsqueda del equilibrio y la contraparte. El derecho a réplica, utilizado por distintos actores políticos, también hizo su parte.

El gobierno tuvo un lugar poco disputado para definir los temas de la agenda. Por un lado, por la centralidad que ocupaba en la organización de la vida social. Por el otro, por la ausencia de figuras nacionales opositoras y la disminución del peso de las élites regionales. Las vedettes periodísticas, caracterizadas por solapar discursos informativos y de opinión, tuvieron menos espacio. Esto se dio mientras aumentaba la legitimidad del gobierno y se reducían las escenas de los medios privados que buscaban disputarle su representatividad.

Las mesas de negociación de las escenas contaban con un gobierno relativamente muy poderoso, con un centro de toma de decisiones muy homogéneo. Del otro lado, convivían distintos propietarios, con estrategias diferentes, con un periodismo que se articulaba como colectivo y se distinguía de las empresas en las que se desempeñaban.

Tercero, desde el comienzo el gobierno cambió ciertas reglas de juego en su vínculo con los medios. Problematizó el rol político de las empresas mediáticas y las identificó con el statu quo anterior. En ese marco, algunos empresarios mediáticos entendieron también que les convenía radicalizar sus escenas para condicionar o echar al gobierno, en línea con la agenda de ciertas élites políticas. Hubo un período de polarización y confrontación política, hasta que el gobierno fue fuertemente refrendado en las urnas. Desde ahí, el gobierno logró ser bien tratado, como el legítimo representante de la ciudadanía, y los empresarios de medios lograron resguardar su propiedad, contar con financiamiento del Estado vía publicidad y continuar con sus negocios más importantes que, en general, no eran los mediáticos. Es decir, si bien la estrategia ofensiva de algunos de ellos fracasó, fueron exitosos cuando se reacomodaron en una posición defensiva. Una forma de resguardarse hasta que cambie la situación política.

\section{Coda: el golpe de Estado, los medios y el MAS}

Este apartado se pregunta cómo se pasó del vínculo mutuamente beneficioso entre gobierno y medios que venimos de describir, a lo que sucedió en el golpe de Estado de 2019. Proponemos un análisis preliminar, con las 
limitaciones que nos presentan tanto la falta de un nuevo trabajo de campo en ese contexto, como el escenario cambiante de la política boliviana.

Aunque el vínculo del gobierno del MAS con los medios se hizo más tirante desde la derrota de febrero de 2016, el vínculo siguió caracterizándose por una agenda informativa compartida hasta octubre de 2019: los medios privados más importantes siguieron siendo escenario de la polarización, antes que protagonistas de ella. Lo que sí se había modificado fuertemente era el panorama político. Por un lado, en 2017 el Tribunal Constitucional habilitó la presentación de Evo Morales a un nuevo mandato, a contramano del resultado del referendo de 2016 y de lo que establecía la Constitución aprobada en 2009. Por otro lado, la oposición aumentó tanto su articulación entre distintos sectores sociales como su radicalización política, al tiempo que enmarcó su disputa con el gobierno como una pelea en "defensa de la democracia”. En un nuevo escenario de polarización, los puntos de encuentro entre oficialismo y oposición fueron cada vez más difíciles (Zegada, 2019).

Las elecciones presidenciales del 20 de octubre de 2019 tuvieron un resultado cerrado. La herramienta de conteo rápido y provisorio se frenó el día de la elección, con $83 \%$ de los votos escrutados y con una ventaja a favor de Evo Morales (MAS) de 45\% a 37\% sobre Carlos Mesa (Comunidad Ciudadana). Para evitar la segunda vuelta, el presidente debía superar el $40 \%$ y $10 \%$ de diferencia con el segundo. Al día siguiente, cuando el conteo rápido se retomó —el oficial no se había detenido-, Morales apareció ganando en primera vuelta. La oposición leyó el resultado y la interrupción, como una artimaña coherente con sus sospechas de la voluntad antidemocrática del gobierno. Las manifestaciones antigubernamentales fueron masivas, se replicaron en distintos puntos del país y, si bien se destacaron los sectores urbanos y las "clases medias tradicionales", de ellas formaron parte distintos actores sociales (Molina, 2019b). La Organización de Estados Americanos (OEA), que había enviado observadores electorales, recomendó, el 10 de noviembre, que se realice una nueva votación y calificó a las elecciones celebradas de "manipulación dolosa", dando a entender que hubo fraude electoral, algo para lo que nunca aportó evidencia empírica (Wolff, 2020) y que otros estudios han refutado (Idobro et al., 2020). Ante ese pedido, Evo Morales anunció nuevas elecciones, pero ese mismo día el jefe del ejército le pidió la renuncia, impidiendo tanto la celebración de nuevas elecciones como la culminación de su mandato. El golpe de Estado se consumó con el nombramiento de la senadora Jeanine Âñez, de Unidad Demócrata, como presidenta interina, en una sesión parlamentaria sin quórum en la que se impidió que los legisladores del MAS, que tenían dos tercios de los representantes, participaran. 
Desde los resultados de octubre, los principales medios privados dedicaron un espacio cada vez mayor para analistas que impulsaban explícitamente la salida de Evo Morales, algo acompañado por la presencia del discurso de distintos sectores opositores que pedían lo mismo.

La ruptura definitiva del vínculo entre el MAS, ya sin gobierno, y los medios sería el 10 de noviembre. La mayoría de los medios siguió compartiendo la agenda informativa, pero con un enfoque distinto: los actores asociados al MAS, ya sea por arriba (dirigentes) o por abajo (sectores sociales y populares movilizados para defender al gobierno depuesto), pasaron a ser vistos como ilegítimos. En algunos casos, se dejó de reportear sobre ellos y en otros se lo hizo desde un framing que los descalificaba. Distintos factores confluyeron para que se produjera ese giro radical.

Como dijimos, el cambio de clivaje más fuerte ya se había producido en las coordenadas del debate público de la política. En su campaña, Carlos Mesa se presentó como el candidato democrático y sembró dudas respecto de si el gobierno haría fraude (Meruvia y Ramírez, 2020). Las líneas editoriales de los medios hacían equilibrio entre esas posiciones y las de un gobierno con el que, si bien los propietarios no coincidían ideológicamente, habían logrado estabilidad y un vínculo relativamente beneficioso. Eso dejó de ser así con el golpe. Si el foco de la estrategia del MAS había estado en la neutralización de los propietarios, puesto que consideraba imposible conquistarlos (García Linera, 2016), la pérdida de los múltiples recursos — tanto simbólicos como materiales- que permitía el gobierno, hizo que su estrategia se hundiera.

Sin embargo, el cambio mediático no fue algo solo definido de arriba hacia abajo. Los periodistas como colectivo también apoyaron la salida de Evo Morales. En ese marco, pidieron reprimendas para los periodistas extranjeros, en su mayoría argentinos, que informaban de las movilizaciones callejeras en contra del derrocamiento del presidente.

La autonomía de los periodistas como colectivo se sostuvo en esos meses de 2019. Tan es así que, cuando lo consideraron pertinente, plantearon su desacuerdo con la línea editorial de sus medios. Esos reclamos no fueron ante los editoriales que reivindicaron, en la mayoría de los medios, el recambio gubernamental. Las diferencias públicas aparecieron, por el contrario, en un pronunciamiento público de los trabajadores de La Razón para desmarcarse de un editorial que calificó lo que sucedía de "golpe de Estado". Esos periodistas también se diferenciaron de las viñetas del historietista $\mathrm{Al}$ Azar, que criticaban el recambio gubernamental, frente a lo cual el dibujante dejó de publicar.

Los sucesos de octubre y noviembre de 2019, mostraron que el colectivo de periodistas sostuvo la capacidad de autorregularse y de trazar fronteras para definir cómo debe proceder su oficio. La paradoja es que eso no los 
hizo ni más plurales ni más balanceados en la cobertura. Por el contrario, parte de sus prácticas coartaron la libertad de expresión de otros.

Un episodio paradigmático fue el asesinato de diez personas en Senkata, El Alto, a manos de fuerzas policiales y del ejército el 19 de noviembre. La versión del gobierno provisional fue reproducida sin cuestionamientos por los medios informativos y se dio por hecho que los manifestantes, que apoyaban a Morales, eran terroristas que habían volado una planta de acopio de gas, algo que se probó falso (Molina, 2019a).

Para ello pesó también el poder relativo de cualquier gobierno en Bolivia: tanto con empresarios de medios que buscan vínculos de cercanía, como con periodistas acostumbrados a que parte central de su trabajo sea buscar sus declaraciones de los políticos. El nuevo gobierno trató a sus antecesores como criminales. Esa agenda fue reproducida por el periodismo de declaración, sin chequeo de fuentes o documentos, con denuncias variadas contra dirigentes del MAS. Sin embargo, era un periodismo de declaración segmentado: los testimonios de los actores asociados al gobierno previo ya no importaban. La contraparte y los controles cruzados que habían caracterizado al trabajo informativo mientras gobernaba Evo Morales, habían quedado atrás. El MAS no era considerado un representante legítimo de la ciudadanía.

Por lo tanto, el recambio gubernamental de noviembre de 2019 generó una rearticulación de los actores: periodistas, empresarios de medios, gobierno y la mayoría de las fuerzas políticas se alinearon en contra del MAS. Desde entonces, sí, en Bolivia apareció una disputa no solo por la interpretación de los hechos, sino también por los hechos mismos. Los medios tomaron una posición cada vez más partidaria.

Un gobierno que había articulado sectores subalternos, movimientos sociales, indígenas y que había propulsado a una nueva élite logró tener un buen vínculo con los medios de comunicación. Fueron tiempos de un relativo balance respecto de la pluralidad de voces que tenían espacio en el sistema mediático. El Golpe de Estado, que contó con el apoyo activo de numerosos sectores, rompió ese esquema.

No obstante, el escenario es dinámico. Este artículo se entrega en la semana posterior a las elecciones presidenciales de 2020. Tras un año de gobierno de facto, el MAS, con Luis Arce como candidato presidencial, obtuvo la victoria en primera vuelta con $55 \%$ de los votos, superando al segundo, Carlos Mesa, por 26\%, refrendando su lugar como la fuerza mayoritaria de la política boliviana desde 2005.

En la época que se abre, resta ver qué persiste y qué no de aquello que emergió con fuerza desde noviembre de 2019. También, cómo serán las articulaciones y disputas entre distintos actores por definir las cuestiones de medios y política. 
Iván Schuliaquer

\section{Referencias bibliográficas}

AGETIC (2017). "Encuesta nacional de opinión sobre Tecnologías de Información y Comunicación”. La Paz. Disponible en https://agetic.gob.bo/pdf/estadotic/ AGETIC-Estado-TICencuestaFinal-v4.pdf.

Albuquerque, A. (2013). Media/politics Connections: Beyond Political Parallelism. Media, Culture Ẽ Society. 35(6), 742-758.

Anria, S. (2018). When Movements Becomes Parties: The Bolivian MAS in comparative perspective. Nueva York: Cambridge University Press.

Archondo, R. (2003). Incestos y blindajes. Radiografia del campo político-periodístico. La Paz: Plural.

Becerra, M. y Mastrini, G. (2006). Periodistas y magnates. Buenos Aires: Prometeo.

Becerra, M. y Mastrini, G. (2009). Los dueños de la palabra. Buenos Aires: Prometeo. Bobbio, N (1996). Derecha e izquierda. Buenos Aires: Taurus.

Della Porta, D. (2008). “Comparative analysis: case-oriented versus variable-oriented research”. En Kieting, M y Della Porta, D., Approaches and Methodologies in the Social Sciences. Cambridge: Cambridge University Press, 198-222.

Exeni, J.L. (2005). MediaMorfosis. La Paz: Plural editores.

Exeni, J.L. (2010). Mediocracia de alta intensidad. La Paz: IDEA.

Fox, E. y Waisbord, S. (2002). Latin politics, global media. Texas: University of Texas Press.

García Linera, A. (2010). "El punto de bifurcación es el momento en el cual se miden los ejércitos”. Entrevista en Svampa, M. et al, Debatir Bolivia. Buenos Aires: Taurus, 137-164.

García Linera, A. (2016). "Cinco puntos débiles de los gobiernos progresistas latinoamericanos". Conferencia en la Universidad de Buenos Aires, 27 de mayo de 2016.

Giavedoni, D. (2010). Los medios en Bolivia: mapa y legislación de los medios de comunicación. La revista del CCC, 9/10. Disponible en https:/www.centrocultural. coop/revista/910/los-medios-en-bolivia-mapa-y-legislacion-de-los-medios-decomunicacion.

Goldstein, A (2014). Medios y política en Brasil durante los gobiernos de Lula y Dilma. Cuestiones Políticas, 30(52), 13-45.

Guerrero, M. (2014). “The 'Captured Liberal' Model of Media Systems in Latin America”. En Guerrero M.y Márquez-Ramírez, M. Media Systems and Communication Policies in Latin America. Basingstoke: Palgrave Macmillan, 43-65.

Hallin, D. y Papathanasopoulos, S. (2002) Political Clientelism and the Media: southern Europe and Latin America in comparative perspective. Media Culture E Society, 24, 175-195.

Hallin, D. y Mancini, P. (2004). Comparing Media Systems. Cambridge: Cambridge University Press. 
Hallin, D. y Mancini, P. (2012). Comparing Media Systems Beyond the Western World. Cambridge: Cambridge University Press.

Idrobo, N., Kronick, D. y Rodríguez, F. (2020). Do Shifts in Late-Counted Votes Signal Fraud? Evidence From Bolivia. Disponible en SSRN: https://ssrn.com/ abstract $=3621475$

Kitzberger, P. (2012). The Media Politics of Latin America's Leftist Governments. Journal of Politics in Latin America, 3, 123-139.

Laclau, E. (2008). Debates y combates. Buenos Aires: Fondo de Cultura Económica.

Lemieux, C. (2010). La subjectivité journalistique. Paris: EHESS.

Levitsky, S. y Roberts, K. (2011). The Resurgence of the Latin American Left. Baltimore: The John Hopkins University.

Lupien, P. (2013). The Media in Venezuela and Bolivia. Latin American Perspectives. 40(3), 226-246.

Meruvia Salinas, G. y Ramírez López, A (2020). Encuadres noticiosos del proceso electoral boliviano. GIGAPP Estudios Working Papers, 7, 172, 642-666.

Molina, F. (2013). “¿Por qué Evo Morales sigue siendo popular?”. Nueva Sociedad, $245,4-14$.

Molina, F. (2015). De la polarización a la hegemonía. Las relaciones entre los medios y el gobierno de Evo Morales. La Paz: Libros nómadas.

Molina, F. (2019a). Hegemonía instantánea: la prensa en la crisis boliviana. Cenital. Consultado el 30 de noviembre de 2019: https:/www.cenital.com/2019/11/29/ hegemonia-instantanea-la-prensa-en-la-crisis-boliviana/64501

Molina, F. (2019b). Bolivia: ¿Golpe o (contra)revolución?. Nueva Sociedad. Consultado el 13 de septiembre de 2020 en: https://nuso.org/articulo/bolivia-golpe-ocontrarevolucion/

Onadem, (2009). Medios a la vista. Informe sobre el periodismo en Bolivia. La Paz: Unir. Peñaranda, R. (2008). “Cómo cubrió Unitel el cabildo cruceño de 2006”. En Peñaranda, R. y Herrera, K., Los canales en cuestión. La Paz: FES, 12-105.

Peñaranda, R. (2014). Control remoto. La Paz: S/D.

Porto, M. (2012). Media power and democratization in Brazil. New York: Routledge.

Quiroga, J. (2017). “10 medios de información bolivianos más leídos en internet”. Consultado el 12 de septiembre de 2020: https://juanquiroga.wordpress.com/ 2017/10/05/10-medios-de-informacion-bolivianos-mas-leidos-en-internet-en-2017/

Ramos Andrade, E. (2011). Neoliberalismo mediático. El Alto: Más claro agua.

Rocha Fuentes, V. (2014). Bolivia: entre la polarización y la contrahegemonía comunicacional. Observatorio Latinoamericano, 14, 92-110.

Rosanvallon, P. (2015). Le bon gouvernement. Paris: Seuil.

Rossi, F. (2017). The Poor's Struggle for Political Incorporation. Cambridge: Cambridge University Press.

Sader, E. (2009). El nuevo topo. Buenos Aires: Siglo XXI.

Sartori, G. (1998). Homo videns: la sociedad teledirigida. Madrid: Taurus. 


\section{Iván Schuliaquer}

Schuliaquer, I. (2014). El poder de los medios. Buenos Aires: Capital Intelectual.

Schuliaquer, I. (2018). La negociación de las escenas mediáticas. Los gobiernos de izquierda y los grandes grupos mediáticos nacionales en América del Sur. Tesis de doctorado. Université Sorbonne Nouvelle-Universidad de Buenos Aires.

Schuliaquer, I. (2020). Les enjeux politiques et économiques des médias en Amérique du Sud entre 2002 et 2019. Annuaire Français de Relations Internationales, 21, 809826.

Sivak, M. (2014).Jefazo. Retrato íntimo de Evo Morales. Buenos Aires: Debate.

Stefanoni, P. (2005). Las nuevas fronteras de la democracia boliviana. Nómadas, 22, 269-278.

Stefanoni, P., y Do Alto, H. (2006). La revolución de Evo Morales. Buenos Aires: Capital Intelectual.

Svampa, M., Stefanoni, P. y Fornillo, B. (2010). Debatir Bolivia. Buenos Aires: Taurus. Villanueva, E. (2008). "The Media in Bolivia”. En Lugo-Ocando, J. (comp.), The Media in Latin America. Nueva York: McGraw-Hill/Open University Press.

Vommaro, G. (2008). Lo que quiere la gente. Los Polvorines: UNGS/Prometeo.

Vommaro, G. y Schuliaquer, I (2014). Definir la escena pública. Medios y política en las democracias sudamericanas. Observatorio Latinoamericano, 14, 139-162.

Waisbord, S. (2013). Media policies and the blindspots of media globalization. Media, culture E' society, 35, 132-138.

Wolff, J. (2020). The Turbulent End of an Era in Bolivia. Revista de Ciencia Política, Ahead of print, 1-24.

Zegada, M. (2006). Partidos en el poder: la ausencia de un sistema de representación política en Bolivia. La Representación política en Bolivia. La Paz: IDEA/PNUD/ ILDIS.

Zegada, M. (2019). El escenario boliviano en 2018. Revista de Ciencia Política, 39 (2), 147-164.

Zegada, M. y Komadina, J. (2014). El espejo de la sociedad. Poder y representación en Bolivia. La Paz: Ceres/Plural. 
Palabras clave:

Gobierno - Medios - Bolivia — Polarización — Periodismo

\title{
Keywords:
}

Government - Media — Bolivia — Polarization — Journalism

\begin{abstract}
The relationship between the governments of Evo Morales and the media in Bolivia went from a public confrontation (2006-2009) to a friendly negotiation (2009-2016). This article historicizes this relationship through national media systems, political communication and communication policies.

What happened in Bolivia is distinct from other cases of the South American «left turn» because the media were not the protagonists of political polarization, but one of its scenarios. That can be explained for three main reasons. First, the strong relative weight of the State and the centrality of the government. Second, the strategy of media owners who, given the stability of a government that was in the opposition to their editorial line, accepted game rules that were convenient for them. Third, the self-regulation of the journalists, who limits intervention on the content from other actors. At the end, the article offers a coda dedicated to what happened when Evo Morales was overthrown.
\end{abstract}

